All articles written by David Simpson unless otherwise attributed. Ideas and items for News Analysis should be sent to David Simpson at the address given on the inside front cover.

\section{Turkey: Camel gets through again}

In the last issue of Tobacco Control (1997;6:86-7) we reported how RJ Reynolds (RJR) had run a magazine advertisement for Camel Trophy "adventure boots" in contravention of Turkey's new tobacco advertising ban, which specifically states that it is illegal to advertise not only tobacco products but also any other goods using the name or logo of a tobacco product. Tobacco control advocates were still trying to persuade the government to enforce its law when RJR came out with another well-tried trick: the "price" advertisement. As the figure shows, the company has thoughtfully included the name and logo of the cigarette brand, all of it arranged, as it happens, in the shape of a cigarette pack. Turkish tobacco control advocates are now faced with a new difficulty: trying to persuade their government's bureaucrats that this amounts to an advertisement. Instead, they might consider asking the bureaucrats to prove that it isn't. But assuming RJR gets away with this

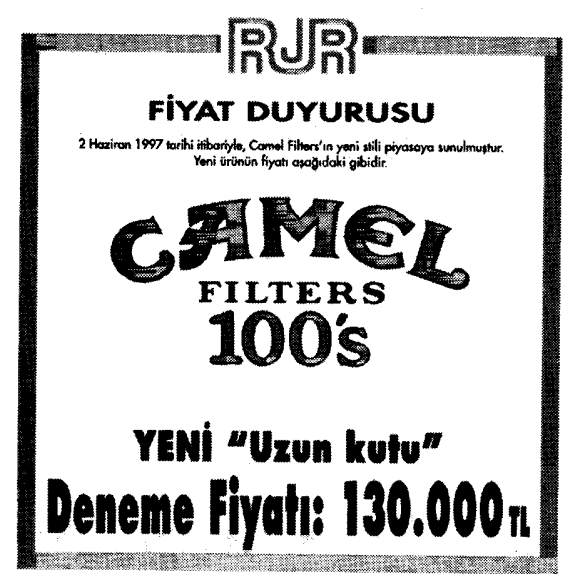

Camel "price" advertisement in Turkish newspaper. one, too, what will they try next? Watch this space.

\section{India: tobacco toothpaste squeezed out}

One of many unusual ways tobacco is used in India is in toothpowder and toothpaste (called "creamy snuff" and sold in toothpaste-type tubes) (figure). There is a widespread misconception in the country that tobacco is good for the teeth-perhaps the "buzz" that users of these products get from nicotine absorbed through the lining of the mouth helps fuel this misconception. This may be a factor, albeit a small one, in India's position at the top of the world's oral cancer league.

Now, after a long battle, tobacco toothpowder and toothpaste have been outlawed. The Supreme Court has upheld the total ban originally imposed by the Union government in 1992 on the use of tobacco in toothpowder and toothpaste. It ruled that the government was justified in imposing the total ban in the public interest following opinions expressed by expert bodies, including the World Health Organisation, that the use of tobacco in oral hygiene preparations should be banned because they cause oral cancer. The court dismissed an appeal by an Ayurvedic company from Madhya Pradesh challenging a judgment of the State High Court upholding the ban.

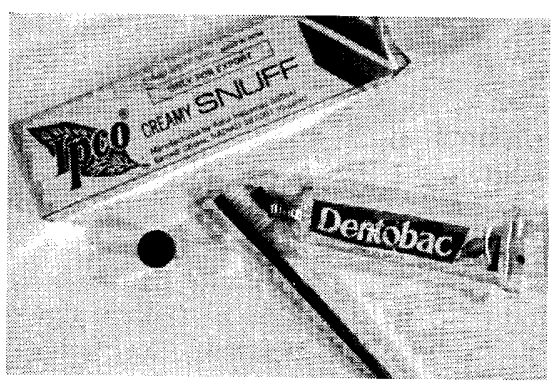

The Supreme Court in India recently upheld a 1992 ban on tobacco toothpaste and toothpowder, called "creamy snuff".

\section{Blaming the children}

In Malaysia, the tobacco industry is funding a government campaign ti் discourage school students from smoking, and penalties include beating with a cane and expulsion. from school. The scheme, launched iros May by the education ministry, look like something that might have beer devised by the tobacco companie themselves, and the fact that it is funded by the Confederation of Malaysian Tobacco Manufacturers does nothing to dispel this suspicion? Under the new rules issued by the ministry, a student caught smoking for the first time will be warned and beaten once with a cane. If the offence is repeated, the student will be caned $\vec{B}$ twice and given another warning. $A^{3}$ third-time offender will be suspended for up to a maximum of 14 days: Those caught smoking for the fourth: time will be expelled.

The vivid and ubiquitous images in Malaysia associating cigarettes witho all things exciting and youthful are among the most notorious in the world. It is thus a master stroke of the industry to get the government ton punish the children, rather than those who feed them such a plethora of positive associations.

Meanwhile, in neighbouring Singa- $\frac{D}{2}$ pore, a teenager has been sent to an juvenile home for two years on? account of his smoking. A judge 0 rejected an appeal by the 16-year-oldస్ boy against the sentence passed lasto October by a lower court after he waso found to possess a packet of cigarettes. The boy had been fined on ${ }^{+}$ three previous occasions for possess- $\frac{0}{0}$ ing tobacco, which is an offence in Singapore for those below the age of 18 years. The judge said the boy needed some "shock treatment", and the spell in the boys' home would pro-o vide the disciplinary action to rehabilitate him.

It seems as improbable that the boy will emerge from custody as a non-smoker as it will be for his counterparts in Malaysia not to catch a strong whiff of the "forbidden fruit" 